\title{
Decline of hypernatraemia as a problem in gastroenteritis
}

\author{
P D MANUEL AND J A WALKER-SMITH \\ Academic Department of Child Health, Queen Elizabeth Hospital for Children, London
}

SUMMARY During the 5-year period 1973-77 there was a considerable change in infant feeding practice (the use of low solute cows' milk formulae instead of high solute formulae and the later introduction of solid foods into the diet) which should have led to a reduced incidence of hypernatraemia among infants admitted to hospital with gastroenteritis. We have compared the incidence of hypernatraemia in such infants admitted during three 12-month periods between January 1973 and December 1977. Our results show there was such a reduction; they also show that hypernatraemia did not occur in infants fed a low solute milk formula alone.

Until recently hypernatraemia was a common biochemical abnormality in infants with gastroenteritis in Western countries, ${ }^{1-2}$ and it is not unknown in developing ones. ${ }^{3}$ This abnormality has been associated with a high mortality rate and particularly with cerebral damage. ${ }^{14}$ This damage is generally due to cerebral oedema or intracranial haemorrhage and is the most serious consequence.

The high incidence of hypernatraemia in infants with gastroenteritis in Western countries has been associated with a high protein intake which stresses the homeostatic mechanisms controlling plasma osmolality, ${ }^{5}$ It has also been associated with hyperosmolar glucose solutions used in the treatment of gastroenteritis, ${ }^{2}$ and with excessive stool water loss caused by intestinal carbohydrate malabsorption together with slow treatment of volume deficits. ${ }^{3}$

Davies called for a return to breast feeding as a protection against hypernatraemia, ${ }^{5}$ but this has happened only to a very limited extent. However, the use of low solute cows' milk formulae is now widespread and this has been accompanied by later introduction of solids into the $\operatorname{diet}^{6}$ (P D Manuel and J A Walker-Smith, 1978, unpublished observations).

There is now evidence that overconcentration of feeds produced by faulty reconstitution ${ }^{7-8}$ is becoming less common, possibly as a result of propaganda aimed at discouraging high solute

Academic Department of Child Health, Queen Elizabeth Hospital for Children

P D MANUEL, lecturer

J A WALKER-SMITH, consultant senior lecturer feeds ${ }^{14}$ although this is not the experience of some workers. ${ }^{9}$

This study was undertaken to find out if the change to low solute feeding has affected the incidence of hypernatraemic dehydration in a population of infants presenting with acute gastroenteritis.

\section{Methods}

A retrospective study was made of all infants admitted with hypernatraemia to the gastroenteritis unit of this hospital during two 12-month periods1 October 1975 to 30 September 1976 and 1 January 1977 to 31 December 1977. Plasma electrolyte concentrations were estimated on admission. Hypernatraemia was defined as plasma sodium concentration of at least $150 \mathrm{mmol} / \mathrm{l}$. Clinical details particularly those relating to reason for admission, feeding history, physical state on admission, and results of investigation and treatment were compared between the two periods and were also compared with results obtained in a prospective study undertaken in the same unit from 1 January 1973 to 31 December 1973 when mainly high solute milks were used in infant feeding. ${ }^{10}$

\section{Results}

Total admissions during the three periods were comparable and show no decrease in incidence of gastroenteritis between 1973 and 1977, Table 1. The sex ratio was similar with slightly more boys 
Table 1 Incidence of hypernatraemia in gastroenteritis admissions

\begin{tabular}{lllll}
\hline & 1973 & $1975-76$ & 1977 \\
\cline { 2 - 3 } & $(n=472)$ & $(n=434)$ & $(n=530)$ \\
\hline Sex ratio M:F & $57 \%$ & $51 \%$ & $56 \%$ \\
Infants with hypernatraemia & $23(4.9 \%)$ & $11(2.5 \%)$ & $5(0.9 \%)$ \\
Infants with $\left(\mathrm{Na}^{+}\right) 160 \mathrm{mmol} / 1$ & $8(1.7 \%)$ & $3(0.7 \%)$ & $1(0.2 \%)$ \\
\hline
\end{tabular}

(54\%). The incidence of hypernatraemia however, fell from 4.9 to $0.9 \%$ during this period. This fall is significant $\mathrm{P}<0 \cdot 01$.

The ethnic origin of infants with hypernatraemia in 1975-76 was European 5, Asian 5, and West Indian 1 , while in 1977 it was 3,1 , and 1 respectively. Mean age at admission of these infants was 10.6 months in 1975-76 and 12.6 months in 1977. Most infants with hypernatraemia were admitted suffering from gastroenteritis-20 in 1973, 11 in 1975-76, and 5 in 1977. Three infants in 1973 had surgical conditions.

In 1975-76 the mean duration of symptoms before admission was 2.8 days (range 2-4) and in 19772.6 days (range 2-3), suggesting no delay in seeking treatment. Seven (64\%) infants in 1975-76 and $5(100 \%)$ infants in 1977 had been seen and treated by a doctor (Table 2). 'Appropriate' treatment was considered to be maintenance of hydration with clear fluids. 'Inappropriate' treatment was the use of such drugs as kaolin, antiemetics, lomotil, or antibiotics. The parents of one infant were advised to add one teaspoonful salt and one teaspoonful sugar to a pint of water; this was considered dangerous. $62.5 \%$ infants were treated inappropriately.

None of the infants admitted with hypernatraemia was being fed low solute milks alone (Table 3). No

Table 2 Outpatient treatment

\begin{tabular}{|c|c|c|}
\hline & $1975-76$ & 1977 \\
\hline $\begin{array}{l}\text { Mean duration of symptoms before } \\
\text { admission }\end{array}$ & $2 \cdot 8$ days & $2 \cdot 6$ days \\
\hline Appropriate treatment & 3 & $1^{*}$ \\
\hline Inappropriate treatment & 5 & 4 \\
\hline Dangerous treatment & $1^{*}$ & $\mathbf{0}$ \\
\hline No outpatient treatment & 2 & $\mathbf{0}$ \\
\hline
\end{tabular}

*Infants who died.

Table 3 Feed at onset of illness

\begin{tabular}{lll}
\hline Feed & $1975-76$ & 1977 \\
\hline 'Doorstep' milk & 2 & 5 \\
High solute milk & 5 & 0 \\
Low solute milk & 4 & 0 \\
Breast milk & 0 & 0 \\
Solid food & 9 & 5 \\
Low solute milk without solid food & 0 & 0 \\
\hline
\end{tabular}

infant was breast fed; $82 \%$ in $1975-76$ and $100 \%$ in 1977 of infants with hypernatraemia were fed solids. Three infants on low solute milks in 1975-76 were also taking significant quantities of solids, while one 6-day-old infant had been fed both a low solute and a high solute milk.

In infants with gastroenteritis dehydration was not generally the main reason for admission. For example, in 1973 only $31.5 \%$ infants admitted were dehydrated. Dehydration however, was pronounced in most infants admitted with hypernatraemia (Table 4).

Other investigations in infants with hypernatraemia admitted in 1975-76 and 1977 showed various abnormalities: 14 of 16 had high concentrations of blood urea; 4 of 16 had significant hypokalaemia $(\mathrm{K}<3.0 \mathrm{mmol} / \mathrm{l}) ; 5$ of $13 \mathrm{had}$ haemoglobin levels $<11 \mathrm{~g} / \mathrm{dl}$ on admission at a time when they were dehydrated; 6 of 8 had acidosis (bicarbonate $<15 \mathrm{mmol} / 1$ or $\mathrm{pH}<7 \cdot 2$ ); 3 of 9 had high WBC counts $\left(>10 \cdot 0 \times 10^{4} / 1\right)$. Bacterial pathogens were found in the stools of none of the 16 infants. Rotavirus was looked for systematically only in 1977 and 2 of the 5 infants were found to have rotavirus on electron microscopical examination of their stools.

14 of the 16 infants required immediate intravenous treatment, generally given as $0.45 \%$ saline in $5 \%$ dextrose to correct the fluid deficit over 48 to 72 hours and 0.18 saline in $5 \%$ dextrose to provide maintenance fluids $(100 \mathrm{ml} / \mathrm{kg}$ for infants below 3 months old, less for older ones). Intravenous treatment was stopped in these infants as soon as possible. Two infants were initially given a glucose electrolyte solution orally, although one developed sugar intolerance and subsequently required treatment intravenously.

The most severe complication, cerebral oedema, occurred in one infant in 1975-76 and one in 1977. Both infants were unconscious and convulsing on admission and both died. None of the other 14 infants suffered from convulsions; other complications are listed in Table 5. Two infants died with hypernatraemia in 1973, one as a direct result, the other also suffered from intussusception and peritonitis.

Table 4 Severity of dehydration

\begin{tabular}{llll}
\hline Degree of dehydration & 1973 & $1975-76$ & 1977 \\
\hline Not dehydrated & 1 & 0 & 1 \\
Slight (3\% or less) & 2 & 0 & 0 \\
Moderate (4-6\%) & 22 & 3 & 1 \\
Severe (7\% or more) & & 8 & 3 \\
Total dehydrated & $22(96 \%)$ & $11(100 \%)$ & $4(80 \%)$ \\
\hline
\end{tabular}


Table 5 Complications of infants admitted with hypernatraemic dehydration

\begin{tabular}{lll}
\hline Complications & $1975-76$ & 1977 \\
\hline Immediate & 1 & 1 \\
Cerebral oedema leading to death & 0 & 0 \\
Convulsions (excluding above) & 3 & 2 \\
Sugar intolerance (transient) & & \\
Late presenting & 0 & 0 \\
Cerebral damage & & \\
Delayed recovery (postenteritis & 1 & 0 \\
$\quad$ syndrome) & 1 & 1 \\
Anaemia & 1 & 0 \\
Further admission with gastroenteritis & 2 & 1 \\
No follow-up & \\
\hline
\end{tabular}

\section{Discussion}

The incidence of hypernatraemia at this hospital has dropped markedly from $4.9 \%$ of admissions in 1973 to $0.9 \%$ in 1977 . The main change likely to have influenced the incidence of hypernatraemia during this period was the widespread change from high solute to low solute milks after DHSS recommendations. ${ }^{11}$ In 1973 most infants were fed high solute milk formulae, by 1977 infants under 6 months were generally taking low solute milks (P D Manuel and J A Walker-Smith, 1978, unpublished observations), while 1975-76 was a transitional period.

None of the 16 infants with hypernatraemia in 1975-76 or 1977 was being fed a low solute milk alone; all 5 infants with hypernatraemia admitted in 1977 were being fed unaltered cows' milk and solids at an age when this mode of feeding is deemed acceptable. The disorder does appear to have become one affecting mainly the older infant (mean age at admission was $11 \cdot 3$ months), and it was only seen in infants with acute gastroenteritis in 1975-76 and 1977.

$95 \%$ of the 39 infants admitted with hypernatraemia were dehydrated compared with about $30 \%$ of infants admitted with gastroenteritis. This, together with the fact that the mean duration of symptoms on admission to hospital was less than 3 days in the hypernatraemic infants, suggests that hypernatraemia is almost completely confined to severely affected infants. Because of the severity of symptoms, most $(87.5 \%)$ infants had been seen by their doctors and treatment been instituted before admission.

It is worrying that the severity of the illness was not recognised or not recognisable, and particularly worrying that inappropriate treatment of symptoms appeared still to be the mainstay of therapy.

It is notable that hypernatraemia was not to any great extent a disorder of immigrants who might be expected to have a poor knowledge of the language and to find reconstitution of milk feeds difficult.
Half the number of infants admitted with hypernatraemia (compared with $56 \%$ of all infants in 1975-76 and 1977 with gastroenteritis), were from the indigenous population.

Management during hospital admission was similar in the three periods, as was the outcome. Three deaths occurred wholly as a result of hypernatraemia, one in each of the 12-month periods, an incidence of major complications of $7.7 \%$ (similar to that reported by Ironside $e t$ al.). ${ }^{2}$ Previous studies reported a high $(30 \%)$ incidence of convulsions during rehydration, ${ }^{14}$ but no infant had convulsions in this study.

Significant hypokalaemia, hyperglycaemia, acidosis, and anaemia were not major problems in management. None of the infants admitted in 1975-76 or 1977 was found to be excreting a recognised bacterial pathogen in stools, although the infant who died wholly from hypernatraemia in 1973 was excreting an enteropathogenic Escherichia coli. In 1977, 2 of 5 infants were excreting rotavirus in their stools, this being a similar incidence to that found among all infants admitted with gastroenteritis to this unit, ${ }^{12}$ but providing further evidence that rotavirus gastroenteritis can be severe.

Transient sugar intolerance occurred in $5(31 \%)$ of 16 infants in 1975-76 and 1977, while delayed recovery (postenteritis syndrome) occurred in only one $(6.67 \%)$ of 16 of infants. This latter figure is less than the incidence of delayed recovery for all infants admitted, ${ }^{13}$ but may reflect the older age group from which the hypernatraemic infants were taken and their good nutritional state.

In conclusion, the incidence of hypernatraemia as a complication of gastroenteritis has declined, probably as a result of the change to low solute milks in the feeding of infants. Where it did occur the infants tended to be older and were being fed a high solute milk formula or unaltered cows' milk together with solids.

\section{Addendum}

The decline in hypernatraemia has continued and in the period 1 November 1978 to 31 October 1979 there were 4 cases of hypernatraemia out of a total of 509 admissions. There were no deaths (M Placzek, 1979, personal communication).

We are grateful to Professor C B S Wood for allowing us to use data collected on his patients.

\section{References}

1 Macaulay D, Blackhall M I. Hypernatraemic dehydration in infantile gastroenteritis. Arch Dis Child 1961; 36: 543-50. 
${ }^{2}$ Ironside A G, Tuxford A F, Heyworth B. A survey of infantile gastroenteritis. $\mathrm{Br}$ Med J 1970; iii: $20-4$.

3 Bart K J, Finberg L. Letter: Single solution for oral therapy of diarrhoea. Lancet 1976: 2: 633-4.

4 Morris-Jones P H, Houston I B, Evans R C. Prognosis of the neurological complications of acute hypernatraemia. Lancet 1967; 2: 1385-9.

5 Davies D P. Protein intake, osmolality homeostasis, and renal function in infancy. Postgrad Med J 1975; 51: Supplement 3, 25.

6 Davies D P. The changing incidence of hypernatraemic dehydration. J Maternal Child Health 1977; September, 354-7.

7 Taitz L S, Byers H D. High calorie osmolar feeding and hypertonic dehydration. Arch Dis Child 1972; 47: 257-60.

8 Smith B A M. Feeding overstrength cows' milk to babies. Br Med J 1974; iv: 741-2.

9 Jones R A K, Belsey E M. Common mistakes in infant feeding: a survey from a London borough. $\mathrm{Br}$ Med $J$ 1978; ii: 112-5.
10 Gribbin M, Walker-Smith J A, Wood C. A twelve month prospective survey of admissions to the gastroenteritis unit of a children's hospital. Acta Paediatr Belg 1976; 29: 69-77.

11 Department of Health and Social Security. Present day practice in infant feeding. London: HMSO, 1974.

12 Walker-Smith J A. Rotavirus gastroenteritis. Arch Dis Child 1978; 53: 355-62.

13 Gribbin M, Walker-Smith J A, Wood C. Delayed recovery following acute gastroenteritis. Acta Paediatr Belg 1976; 29: 167-76.

14 Davies D P, Ansari B M, Mandal B K. Letter: Hypernatraemia and gastroenteritis. Lancet 1977; 1: 252.

Correspondence to Dr P D Manuel, Academic Department of Child Health, Queen Elizabeth Hospital for Children, Hackney Road, London E2 8PS.

Received 24 April 1979 